\title{
Sexuality in Adolescent Boys with Autism Spectrum Disorder: Self-reported Behaviours and Attitudes
}

\author{
Jeroen Dewinter • Robert Vermeiren • \\ Ine Vanwesenbeeck · Jill Lobbestael • \\ Chijs Van Nieuwenhuizen
}

Published online: 12 September 2014

(C) Springer Science+Business Media New York 2014

\begin{abstract}
Differences in sexual functioning of adolescents with and without autism spectrum disorder (ASD) are understudied. In the current study, self-reported sexual behaviours, interests and attitudes of 50 adolescent boys, aged 15-18, with at least average intelligence and diagnosed with ASD, were compared with a matched general population control group of 90 boys. Results demonstrated substantial similarity between the groups in terms of sexual behaviours. The only significant difference was that boys with ASD reacted more tolerant towards homosexuality compared to the control group. Results reveal that sexuality is a normative part of adolescent development in highfunctioning boys with ASD. Hence, attention should be given to this topic in education and mental health care.
\end{abstract}

Keywords Autism - Asperger's disorder · Sexuality · Sexual behaviour

J. Dewinter · C. Van Nieuwenhuizen

Tranzo, Scientific Centre for Care and Welfare, Tilburg

University, PO Box 90153, 5000 LE Tilburg, The Netherlands

J. Dewinter $(\square) \cdot$ C. Van Nieuwenhuizen

Centre for Child and Adolescent Psychiatry, GGzE,

PO Box 909 (DP1104), 5600 AX Eindhoven, The Netherlands

e-mail: jeroen.dewinter@antwerpen.be

R. Vermeiren

Department of Child and Adolescent Psychiatry, Curium-

LUMC, PO box 15, 2300 AA Leiden, The Netherlands

R. Vermeiren

VU Medical Centre, Amsterdam, PO Box 303,

1115 ZG Duivendrecht, The Netherlands

\section{Introduction}

Over the past few decades, sexuality has become increasingly accepted as a normative part of adolescent development (Tolman and McClelland 2011), yet little is known about sexuality in high-functioning adolescents with autism spectrum disorder (ASD) (Dewinter et al. 2013). The aim of this study was to investigate sexual behaviours and attitudes in a group of adolescent boys diagnosed with ASD and with at least average intelligence. Findings on normative sexual behaviours in the general Western adolescent population serve as a reference point. The possible influence of ASD features on the development of sexual behaviour, as well as the limited research on sexuality and ASD, will be discussed to underpin the hypotheses for this research.

\section{Adolescent Sexual Behaviours}

Until now, research on sexuality in adolescent samples has focussed primarily on sexual behaviours. Other aspects of

I. Vanwesenbeeck

Interdisciplinary Social Science, Utrecht University,

PO Box 80140, 3508 TC Utrecht, The Netherlands

I. Vanwesenbeeck

Rutgers WPF, PO Box 9022, 3506 GA Utrecht, The Netherlands

J. Lobbestael

Department of Clinical Psychological Science, Faculty of

Psychology and Neuroscience, Maastricht University,

Universiteitssingel 40, 6200 MD Maastricht, The Netherlands

J. Lobbestael

RINO Zuid Postdoctoral Training Institute, PO Box 826,

5624 AD Eindhoven, The Netherlands 
adult sexuality, however, such as sexual desire, function, arousal and experience, are also part of early adolescent functioning. Studies on these aspects remain scarce (Diamond and Savin-Williams 2009; Fortenberry 2013). Scientific publications on adolescent sexuality in Western countries reveal a decline in age for the onset of puberty. Earlier age for sexual debut was also found, for solo as well as partnered acts. This decline in age of first sexual experiences has stabilised during recent decades. Solo sexual experiences, such as masturbation, are common in early adolescent boys and are shown by about half of the boys at age 12 (Fortenberry 2013; Moore and Rosenthal 2006). A specific sequence in partnered sexual experiences and behaviours has appeared in different studies-starting at around age 13 with kissing, and moving on to embracing, petting above clothes, touching breasts and genitals, masturbating the other, oral stimulation and vaginal intercourse (around $60 \%$ at age 18 in the case of the latter) (de Graaf et al. 2012; Diamond and Savin-Williams 2009; Moore and Rosenthal 2006). Only a minority of adolescents reported anal intercourse. Around $90 \%$ of adolescents defined themselves as heterosexual, although uncertainty about sexual orientation is common in adolescents (Diamond and Savin-Williams 2009; Moore and Rosenthal 2006).

\section{ASD and Sexuality}

There is a dearth of knowledge on the prevalence of solo and partnered sexual behaviours, as well as on the age of sexual debut, in adolescents with ASD. Although there is no evidence that physical maturation of adolescents with ASD differs from that of typically developing peers (Gabriels and Van Bourgondien 2007), it can be assumed that ASD features in adolescents influence sexual development and functioning in different ways. Mechanisms that might play a part are described below.

First, behavioural and information processing characteristics in ASD, such as specific sensory interests (e.g., interest in specific aspects such as hair), hyper- or hyposensitivity (e.g., hypersensitivity towards touching), preoccupations, and compulsiveness (e.g., specific rituals), may directly influence sexual experience and behaviours of people with ASD. Second, qualitative impairments in ASD in the social and communicative domain are also likely to have an impact on the sexual development of adolescents with ASD. These features frequently hamper the development of friendships and romantic relationships, diminish opportunities to learn about sexuality from peers and influence one's judgement to apply sexuality in a socially acceptable way or in interpreting (sexual) intentions of others. Communicative impairments might result in literal or incorrect interpretations of information relating to sexuality. On both explicit and implicit levels, information about sexuality and sexual codes might not be clear to people with ASD (Gabriels and Van Bourgondien 2007). In addition to the role of specific ASD features, characteristics of the social contexts of the boys with ASD could also influence their sexual development (Smith et al. 2005). Sexual socialisation of adolescents by parents, teachers, and other caregivers might differ depending on their opinions regarding sexuality and ASD, their skills in discussing these topics, or their concerns about the skills of their children with ASD. Societal views on sexuality and autism also influence education and parenting. Bertilsdotter Rosqvist (2013) discerned different views on sexuality in autism over the past few decades, varying from the denial of sexuality in people with ASD (asexuality discourse) to a focus on abnormality (deficit discourse), or a normative discourse based on sexual development of neurotypical people (neuronormative discourse) versus an autistic sexuality.

\section{Research on Sexuality and ASD}

Recently, the existing research on sexuality and ASD was reviewed according to the three domains discerned by Tolman and McClelland (2011): behavioural aspects of sexuality, sexual selfhood, and sexual socialisation (Dewinter et al. 2013). Given the aim of the current study, only findings on behavioural aspects are discussed below. This knowledge of sexual behaviour in people with an ASD should be interpreted in light of different methodological limitations. First, the characteristics of the groups studied differ, both between and within studies, regarding participants' intellectual capacities, autism features, sex, age, and level of functioning. Most of the available results on sexuality and ASD are based on the study of adults or mixed-age groups. Second, most studies included small numbers of participants. Both these aspects hamper comparability and generalizability of the available findings. Third, even though adolescents display most sexual behaviours in private, researchers mostly approached caregivers or parents as informants (Haracopos and Pedersen 1992; Hellemans et al. 2007; Stokes et al. 2007; Stokes and Kaur 2005). The validity of data based on observations by others is questionable and different authors have stressed the importance of questioning the people with ASD themselves (Haracopos and Pedersen 1992; Hellemans et al. 2007). Studies using selfreport only included adult participants (Byers et al. 2013; Gilmour et al. 2012; Hénault and Attwood 2006; Ousley and Mesibov 1991).

The results to date reveal that the majority of people with at least average intelligence and ASD are sexually active-mostly in a solitary manner, in the form of sexual interest and masturbation (Byers et al. 2013; Haracopos 
and Pedersen 1992; Hellemans et al. 2007; Ousley and Mesibov 1991), with fewer people having partner-oriented sex (Byers et al. 2012; Hellemans et al. 2007; Hénault and Attwood 2006). Findings on sexual orientation suggest a higher prevalence of homo- or bisexual feelings in people with ASD compared to the general population (Byers et al. 2013; Gilmour et al. 2012; Hellemans et al. 2007). Only a small group of adults with ASD reported feelings of asexuality (Gilmour et al. 2012). A number of studies and case reports describe sexual problems (e.g., offensive behaviours) and specific sexual behaviours (e.g., paraphilias) in people with ASD (Baron-Cohen 1988; Bleil Walters et al. 2013; Chan and Saluja 2011; Cooper et al. 1993; Griffin-Shelley 2010; Hellemans et al. 2007; Kohn et al. 1998; Milton et al. 2002; Murrie et al. 2002; Ray et al. 2004; Silva et al. 2002). It remains undetermined, however, whether there is a higher prevalence of problematic behaviour and negative sexual experiences in people with ASD compared to the general population. Mandell et al. (2005) found sexual victimisation in one out of six children with ASD treated in community mental health services, although another study (Mehtar and Mukaddes 2011) revealed lower rates of trauma history. The victimised children in the first study had a higher risk of becoming sexually aggressive and abusive themselves. Furthermore, different studies describe other problematic aspects of sexual development and functioning in people with ASD, such as gender identity problems (de Vries et al. 2010), excessive masturbating, inadequate masturbation techniques, and masturbation in public places (Haracopos and Pedersen 1992; Hellemans et al. 2007).

\section{The Current Study}

The main goal of this study was to gain insight into the prevalence of sexual behaviours and experiences of adolescent boys clinically diagnosed with ASD, by focussing on a homogeneous group in terms of intellectual ability, cultural background, age, and diagnosis. The expectation was that these findings would offer insight into the normativity of different sexual behaviours and experiences in high-functioning adolescent boys with ASD. A second goal was to compare self-reported sexual behaviours, attitudes, and interests of adolescent boys with ASD with those of matched peers in the general population. Four basic hypotheses (H1-4) were put forward. First, boys with ASD and the control group have comparable lifetime experience with solitary sexual behaviours such as masturbation, experience with orgasm, and sexual interest (e.g., viewing explicit sexual materials) (H1). Although it is accepted that physical sexual maturation does not differentiate the ASD and control groups, earlier studies found lower percentages of people with ASD reporting solo sex. We expected, however, that reliance on parent- and caregiver-report explains the lower frequencies regarding solo sexual experiences in the ASD group, resulting in an underestimation of solo sexual experience in earlier studies. Second, given the social limitations inherent in ASD, the expectation was that boys in the ASD group have less experience with partner-oriented sexual behaviours (H2). This could be explained by the social and communicative impairments of the boys with ASD. Third, higher frequencies of victimisation and offending behaviours in the ASD group were also assumed, based on earlier research (Mandell et al. 2005) (H3). Finally, following earlier findings (Hellemans et al. 2007), we expected higher levels of homosexual experiences and homo- or bisexual feelings in the ASD group (H4). Alongside these four hypotheses, we explored attitudes and online behaviours relating to sexuality. Both these aspects remain understudied in adolescents with ASD. Sexual opinions and attitudes are related to sexual behaviour (Fortenberry 2013), making exploration relevant. Sexually explicit media can also influence sexual behaviour in adolescents (Braun-Courville and Rojas 2009). However, in adolescents with ASD, rates of social media use seemed low (Mazurek et al. 2012) and not as important for romantic learning compared with controls (Stokes et al. 2007). Self-report on the use of sexually explicit media and use of internet for sexuality related means by adolescents with ASD is not available.

\section{Methods}

Participants

Participants in this study were native Dutch and Belgian boys aged 15-18, with at least average intelligence and diagnosed by mental health professionals with an Autistic Disorder or Asperger's Disorder (APA 2000). All participants were high-functioning; they had to attend regular classes or score above 70 for full scale IQ (following Hellemans et al. 2007) on a standard intelligence measure. Since sexual development gains momentum during adolescence, the age range of the participants was limited to increase homogeneity. Given the differences in sexual development and behaviours between boys and girls, only boys were recruited (Byers et al. 2013; Tolman et al. 2010). The prevalence of ASD is also higher in boys compared with girls: 2:1 for Autistic Disorder; 4:1 for Asperger's Disorder (Levy et al. 2009). Comorbid disorders were no cause for exclusion except in the case of acute psychotic symptoms. Adolescents living in institutions for adolescents with ASD and average intelligence, as well as others living at home and receiving different types of care, were approached. 


\section{Controls}

The control data were selected from a large survey study on sexual health in young people aged between 12 and 25 in the Netherlands. The authors (de Graaf et al. 2012) of this survey kindly provided us with the original 'Sex under the age of 25 II' data. The participants in the original study were recruited in schools and through Municipal Administrative Systems. They completed the surveys at home or in classrooms. No information was available regarding psychiatric diagnosis in the control group. Although it is unknown if any of the boys in the control group were diagnosed with a psychiatric or developmental disorder, less than the population prevalence (e.g., .6-1.16\% for ASD (Levy et al. 2009)) is to be expected. Matching took place based on age, ethnicity, educational level, and sex.

\section{Materials}

\section{Sexual Functioning}

All boys completed a computerized survey on sexual health that was developed for the 'Sex under the age of age 25 II' study by de Graaf et al. (2012), from which the controls were drawn. Questions in this survey were easily understandable formulated and specific concepts were explained next to each question. Most questions were closed multiple-choice answer formats. These characteristics made the questions suited to adolescents with ASD. The survey consisted of a maximum of 172 questions and was automatically adjusted to the characteristics and responses of the participants, so that respondents did not receive inapplicable questions. The survey covered a range of themes relating to sexuality: love and relationships, sexual experiences, partners, evaluation of sexual contacts, attitudes and knowledge, sexual orientation, use of condoms and other contraceptives, offensive behaviour and victimisation, sexual problems, internet behaviours, alcohol and drug use, communication, and sex education. The report on the results of the 'Sex under the age of 25 II' survey describes the construction of the questionnaire. Most items were selected from existing scales and questionnaires. There is no external criterion to test validity. Face validity, however, is good.

Five scales measuring attitudes and feelings were computed. Item scores for each scale were added up and divided by the number of items in the scale. The scale 'Permissiveness towards sexual intercourse' $(\alpha=.69)$ consisted of four four-point Likert-type items (e.g., 'How do you feel about intercourse before marriage?') scored from 1 ('not good at all') to 4 ('totally good'). Higher scores reflect a more liberal attitude towards sexual contacts. 'Gender roles' $(\alpha=.69)$ included four items (e.g.,
'How do you feel about a girl chatting up a boy?') with five response levels from 1 ('not good at all') to 5 ('totally good'). Higher scores on this scale reflect less genderrelated permissiveness (e.g., a boy can have sex with a lot of girls, but a girl cannot have sex with a lot of boys). The scale 'Acceptance of homosexuality' $(\alpha=.67)$ consisted of three questions (e.g., 'How do you feel about two boys making love?' and 'If your best friend tells you he is gay, would you stop the friendship?'), with five answering categories from 1 ('not good at all') to 5 ('totally good') for the first example and 1 ('sure I would') to 5 ('sure I wouldn't') for the second. Higher scores on this scale reflect more tolerance of homosexuality. 'Positive feelings about sexuality' $(\alpha=.76)$ had three items (e.g., 'Sex is important to me') and 'Negative feelings about sexuality' ( $\alpha=.84$ ) contained five items (e.g., 'I feel guilty after masturbating') with five possible responses for each from 1 ('totally agree') to 5 ('totally disagree'). Higher scores reflect less positive and less negative scores about sexuality respectively.

\section{ASD}

All boys were clinically diagnosed with either Autistic Disorder or Asperger's Disorder before they entered the study. ASD features were assessed by administration of the Autism Diagnostic Observation Schedule (ADOS) module 4 (fluent speech) (Lord et al. 1999) to the participating boys and the Autism Diagnostic Interview-Revised (Rutter et al. 2003) to their parents. The first author (JD), who is qualified for research purposes in both ADI-R and ADOS, conducted all administrations.

\section{Procedure}

This study was approved after ethical review (Medical Ethical Committee reference NL34563.097.11 in the Netherlands and approval 4112 by the Institutional Review Board ZNA/OCMW in Antwerp, Belgium). Professionals, working with boys with ASD in different institutions and schools, invited eligible participants. None of the participants was dependent on the researchers for treatment. Parents and adolescents received an information letter and leaflets. Potential participants could contact the researcher to obtain further information or to refuse participation. Parents were contacted again after 10 days if no response was received. We also posted a call for participation on the website of the Dutch Autism Association.

Administration of the survey and ASD assessments took place at home, at school or in the hospital or institution where the adolescent resided. Participants received additional information on the study at the start of every appointment. All boys and their parents gave written informed consent. In most cases, the ADOS was conducted before the completion 
of the survey on sexuality, because this provided the opportunity for the boys to become acquainted with the researcher. The boys completed the online survey (SO25II) in private with the researcher nearby, so that they could ask for help or additional information. They were told that a variety of behaviours and opinions relating to sexuality would be asked about, in which they may or may have not been involved. They received a neutral username and password to $\log$ in anonymously. Some boys asked for help or preferred to have the questions read aloud by the researcher. The adolescents regularly reported personal experiences or asked for clarification of questions. Two boys preferred to complete the survey on their own at home. It took $90 \mathrm{~min}$ for the boys to complete the ADOS and survey. The administration of the ADI-R took on average $2 \mathrm{~h}$. Participants received a $€ 5$ voucher after completing the survey.

\section{Power Analysis and Statistical Analyses}

According to a priori power analysis $(\alpha=.05,1-$ $\beta=.80$ ), a group size of 50 participants was necessary in order to detect medium- to large-sized effects between the two groups (ASD and control) when looking at differences between means and frequencies (Cohen 1988). Data were analysed using SPSS21. Mann-Whitney $U$ tests (exact twosided) were used to compare medians and group distributions. Chi square $\left(\chi^{2}\right)$ tests were run to compare frequencies and exact two-side probabilities were reported. The Fisher's exact test, the exact probability of Chi square, was used when the expected frequencies in cells were too low, due to the relatively small sample size. The large number of comparisons inflates the risk of type I errors. A Bonferroni correction would result in higher risk for type II errors. Therefore, a type I error rate of $\alpha=.01$ was adopted. Cramer's $V$ is the effect size for significant results of Chi square $\left(\chi^{2}\right)$ tests. Given the power calculation, only medium (Cramer's $V=.3-.5$ ) to large (Cramer's $V>.5$ ) effects are interpreted. Effect size $r$ is reported for Mann-Whitney U tests. Cohen (1988) suggested that $r=.1$ represents a small effect, $r=.3$ a medium effect, and $r=.5$ a large effect. Since questions were omitted depending on earlier answers of participants, not all boys had to answer all questions, so it will be explicitly noted if total $N$ was lower than 50 .

\section{Results}

\section{Sample Characteristics}

One hundred and forty-six boys and their parents received information about this project. Fifty-one boys agreed to participate and completed the computerized survey on sexual health. Reasons for non-participation varied. In
Table 1 Characteristics of participants with ASD

\begin{tabular}{|c|c|c|c|c|}
\hline & & & \multicolumn{2}{|c|}{$A S D \%(n)(N=50)$} \\
\hline \multicolumn{5}{|l|}{$A S D$} \\
\hline \multicolumn{3}{|l|}{ Autistic disorder } & \multicolumn{2}{|c|}{$40(20)$} \\
\hline \multicolumn{3}{|c|}{ Asperger's disorder } & \multicolumn{2}{|c|}{$60(30)$} \\
\hline \multicolumn{5}{|c|}{ Comorbid disorders } \\
\hline \multicolumn{3}{|c|}{ Attention deficit hyperactivity disorder } & \multicolumn{2}{|c|}{$24(12)$} \\
\hline \multicolumn{3}{|l|}{ Learning disorders } & \multicolumn{2}{|l|}{$8(4)$} \\
\hline \multicolumn{3}{|l|}{ Anxiety disorders } & \multicolumn{2}{|l|}{$4(2)$} \\
\hline \multicolumn{3}{|c|}{ Posttraumatic stress disorder } & \multicolumn{2}{|l|}{$2(1)$} \\
\hline \multicolumn{3}{|l|}{ Tourette's disorder } & \multicolumn{2}{|l|}{$2(1)$} \\
\hline \multicolumn{5}{|l|}{ Living situation } \\
\hline \multicolumn{3}{|l|}{ Home } & \multicolumn{2}{|l|}{$70(35)$} \\
\hline \multicolumn{3}{|l|}{ Group home } & \multicolumn{2}{|l|}{$16(8)$} \\
\hline \multicolumn{3}{|c|}{ Residential psychiatric treatment } & \multicolumn{2}{|l|}{$12(6)$} \\
\hline \multicolumn{3}{|c|}{ Day care treatment } & \multicolumn{2}{|l|}{$2(1)$} \\
\hline \multicolumn{5}{|l|}{ Educational level } \\
\hline \multicolumn{3}{|l|}{ High } & \multicolumn{2}{|l|}{$42(21)$} \\
\hline \multirow{2}{*}{\multicolumn{2}{|c|}{ Low }} & & \multicolumn{2}{|l|}{$58(29)$} \\
\hline & & $m$ & $s d$ & Range \\
\hline Age & ASD & 16.65 & .78 & $15.04-18.02$ \\
\hline \multirow[t]{3}{*}{ Intelligence (IQ) } & $\begin{array}{l}\text { Full scale } \\
\qquad(n=42)\end{array}$ & 104.29 & 15.62 & $76-142$ \\
\hline & $\begin{array}{l}\text { Verbal scale } \\
\quad(n=40)\end{array}$ & 107.83 & 15.15 & $80-142$ \\
\hline & $\begin{array}{l}\text { Performal scale } \\
\quad(n=40)\end{array}$ & 100.68 & 16.26 & $70-140$ \\
\hline
\end{tabular}

most cases, parents stated that the psychological condition of their son did not allow for participation, or mentioned that their son had a lack of interest in sexuality or refused to talk about sexuality. No other information on the nonresponders was available. One participant reported that he did not dare to answer honestly questions pertaining to homosexuality, resulting in the exclusion of his data from the analysis. The remaining 50 boys (Table 1) were matched to the maximal possible stratified random sample selected from the study 'Sex under the age of 25 II' ( $N=3,926$ boys and 3,915 girls) (de Graaf et al. 2012).

The control group consisted of 90 boys living in the Netherlands. Matching took place based on age (15-18), sex (male), ethnicity (Dutch) and educational level (low, i.e., prevocational, vs. high). Both groups did not differ regarding age $(t(138)=.27, p=.79)$ or educational level $\left(\chi^{2}(1)=.40, p=.84\right)$.

Autism Features

Mental health professionals in multi-disciplinary teams diagnosed all participants in the ASD group (Autistic 
Table 2 Sexual behaviours and age of first experience

a Not applicable

b Question asked to boys with other partnered experience ASD $n=29$, controls $n=65$

c Fisher's exact was used

\begin{tabular}{|c|c|c|c|c|c|c|c|c|}
\hline & \multicolumn{4}{|c|}{ Experienced this } & \multicolumn{4}{|c|}{ Age first time } \\
\hline & $\begin{array}{l}\text { ASD \% } \\
(n)(N=50)\end{array}$ & $\begin{array}{l}\text { Control \% } \\
(n)(N=90)\end{array}$ & $X^{2}$ & $p$ & $\begin{array}{l}\text { ASD } \\
m\end{array}$ & $\begin{array}{l}\text { Control } \\
m\end{array}$ & $t$ & $p$ \\
\hline Has been in love & $82(41)$ & $85.6(77)$ & .31 & .63 & $\mathrm{n} / \mathrm{a}^{\mathrm{a}}$ & $\mathrm{n} / \mathrm{a}^{\mathrm{a}}$ & $\mathrm{n} / \mathrm{a}^{\mathrm{a}}$ & $\mathrm{n} / \mathrm{a}^{\mathrm{a}}$ \\
\hline Masturbation & $94(47)$ & $90.0(81)$ & $\mathrm{n} / \mathrm{a}^{\mathrm{c}}$ & .54 & 12.93 & 13.47 & 1.44 & .15 \\
\hline Orgasm & $90(45)$ & $85.6(77)$ & .57 & .60 & 13.34 & 13.63 & .85 & .40 \\
\hline Dating & $70(35)$ & $73.3(66)$ & .18 & .70 & 12.99 & 12.65 & -.61 & .54 \\
\hline French kissing & $56(28)$ & $65.6(59)$ & 1.25 & .28 & 14.50 & 13.99 & -1.13 & .26 \\
\hline Petting with clothes on & $52(26)$ & $63.0(57)$ & 1.70 & .21 & 14.96 & 14.66 & -.82 & .41 \\
\hline Masturbating another & $40(20)$ & $41.0(37)$ & .02 & 1.00 & 15.55 & 15.50 & -.17 & .86 \\
\hline Being masturbated & $34(17)$ & $37.0(33)$ & .10 & .85 & 15.32 & 15.38 & .15 & .88 \\
\hline Oral sex ${ }^{\mathrm{b}}$ (active) & $22(11)$ & $25.5(23)$ & .06 & .82 & 15.50 & 15.72 & .45 & .66 \\
\hline Oral $\operatorname{sex}^{\mathrm{b}}$ (passive) & $22(11)$ & $32.2(29)$ & .37 & .65 & 15.42 & 15.81 & .91 & .37 \\
\hline Vaginal intercourse & $24(12)$ & $33.3(30)$ & 1.33 & .34 & 15.42 & 16.03 & 1.61 & .12 \\
\hline Anal $\operatorname{sex}^{b}$ & $6(3)$ & $3.3(3)$ & $\mathrm{n} / \mathrm{a}^{\mathrm{c}}$ & .37 & 14.17 & 15.17 & 1.06 & .35 \\
\hline Only feels attracted to girls & $88(44)$ & $93.3(84)$ & $\mathrm{n} / \mathrm{a}^{\mathrm{c}}$ & .35 & $\mathrm{n} / \mathrm{a}^{\mathrm{a}}$ & $\mathrm{n} / \mathrm{a}^{\mathrm{a}}$ & $\mathrm{n} / \mathrm{a}^{\mathrm{a}}$ & $\mathrm{n} / \mathrm{a}^{\mathrm{a}}$ \\
\hline $\begin{array}{l}\text { Tried or would like to try } \\
\text { making love with a boy }\end{array}$ & $18(9)$ & $12.2(11)$ & .87 & .45 & $\mathrm{n} / \mathrm{a}^{\mathrm{a}}$ & $\mathrm{n} / \mathrm{a}^{\mathrm{a}}$ & $\mathrm{n} / \mathrm{a}^{\mathrm{a}}$ & $\mathrm{n} / \mathrm{a}^{\mathrm{a}}$ \\
\hline
\end{tabular}

Disorder or Asperger's Disorder) before inclusion. Of the 50 boys with ASD, 45 agreed to the administration of ADOS after inclusion. Thirty-four of these 45 boys (sensitivity $S E=.76)$ met the cut-off scores for ASD on the ADOS module 4 algorithm (16 Autistic Disorder, 18 Asperger's Disorder), and 31 ( $S E=.69$ ) when using the new Gotham criteria, developed for ADOS module 3 (Gotham et al. 2007). Bastiaansen et al. (2011) found a comparable sensitivity of the ADOS in their sample of high-functioning adults: in their sample, a cut-off score of five resulted in a higher sensitivity, in balance with specificity. In our group, using the revised algorithm and cut-off score of five, sensitivity increased to .90. Thirty-six parents agreed for the ADI-R to be administered, of which 14 met the algorithm cut-off scores (sensitivity $S E=.39$ ). Applying the convention of allowing a diagnosis of ASD if the ADI-R scores meet the cut-off on two of three domains and miss the cut-off on the third by one point (Rutter et al. 2003) resulted in 24 positives ( $S E=.67$ ). Comparison of the groups that did and did not meet the cutoff scores of both ADI-R and ADOS revealed no major differences in relation to sexual behaviours.

\section{Sexual Behaviour}

Comparable percentages of boys in the ASD and control group reported having experienced different romantic and sexual behaviours-solo as well as partnered (Table 2).

The majority of boys with ASD had been in love ( $82 \%)$ and dated a partner $(70 \%)$. Almost all boys reported masturbation (ASD $94 \%$ ) and had experienced an orgasm (ASD $90 \%$ ). About half of the boys at this age confirmed
French kissing and petting their partner above clothes. A substantial number of boys had experience with manual and oral stimulation. About a quarter of the boys with ASD reported vaginal intercourse. Few boys had experienced anal sex. Both groups reported comparable ages of sexual debut (first time engaging in these different sexual behaviours). These results support the first hypothesis and refute the second (H1-2).

Of the boys with ASD with partnered sexual experience $(n=26), \quad 11-50 \%$ reported sexual problems (e.g., diminished sexual arousal, delayed or premature orgasm and pain), comparable with rates in the control group. However, this group was too small to interpret these findings. Only a small number of boys reported that they had been forced into sexual behaviours $(n=2$ in the ASD group) or had used sexual coercion (ASD $n=3$ ) (H3).

Most boys, in both the ASD and the control group, reported feeling attracted only to girls. Some reported having made love to another boy or being willing to try this out. No significant differences $(p>.01)$ between the ASD group and control group were found. These findings result in the rejection of the fourth hypothesis (H4).

\section{Attitudes Towards Sexuality}

Participants with ASD and controls reacted equally permissively to statements about sexual contacts in different male-female relationships (Table 3 for scale means, item frequencies are added in text for illustration).

Double standards in the role of boys and girls in flirting and sexual behaviour (gender role) were not found. The 
Table 3 Feelings towards sexuality, gender roles and homosexuality

a $\operatorname{ASD} n=50$, Controls

$n=90$

b ASD $n=45$, Controls $n=86$

\begin{tabular}{lllllrr}
\hline & $\begin{array}{l}\text { ASD } \\
\text { Median }\end{array}$ & $\begin{array}{l}\text { Controls } \\
\text { Median }\end{array}$ & $U$ & $z$ & $p$ & $r$ \\
\hline Permissiveness towards sexuality $^{\mathrm{a}}(1-4)$ & 3.25 & 3.25 & $2,134.0$ & -.51 & .61 & -.04 \\
Gender roles $^{\mathrm{a}}(1-5)$ & 3.12 & 3.00 & $2,118.5$ & -.58 & .57 & .05 \\
Acceptance of homosexuality $^{\mathrm{b}}(1-5)$ & 4.00 & 3.33 & $1,012.0$ & -4.50 & $<.01$ & .39 \\
Positive feelings about sexuality $^{\mathrm{a}}(1-5)$ & 2.67 & 2.67 & $1,971.0$ & -1.22 & .22 & .10 \\
Negative feelings about sexuality $^{\mathrm{a}}(1-5)$ & 4.60 & 4.40 & $2,228.5$ & -.09 & .93 & -.01 \\
\hline
\end{tabular}

Table 4 Use of explicit sexual materials and online sexuality during last 6 months

\begin{tabular}{lclrr}
\hline Media & $\begin{array}{l}\text { ASD \% } \\
(\mathrm{n})(N=50)\end{array}$ & $\begin{array}{l}\text { Controls } \% \\
(\mathrm{n})(N=90)\end{array}$ & \multicolumn{1}{l}{$X^{2}$} & \multicolumn{1}{l}{$p$} \\
\hline Porn magazine & $36(18)$ & $36.7(33)$ & .01 & 1.00 \\
Video clip with nudity & $70(35)$ & $75.6(68)$ & .51 & .55 \\
Sex movie on TV & $22(11)$ & $30.0(27)$ & 1.04 & .33 \\
Sex movie on DVD & $8(4)$ & $14.4(13)$ & 1.25 & .30 \\
Porn on the internet & $76(38)$ & $73.3(66)$ & .12 & .84 \\
Sex line & $4(2)$ & $3.3(3)$ & $\mathrm{n} / \mathrm{a}^{\mathrm{a}}$ & 1.00 \\
Any & $86(43)$ & $87.8(79)$ & 2.54 & .88 \\
On the internet & & & & \\
$\quad$ Talked about sex & $46(23)$ & $27.7(25)$ & 4.74 & .04 \\
Flirted & $38(19)$ & $36.7(33)$ & .02 & 1.00 \\
$\quad$ Showed genitals or & $8(4)$ & $2.2(2)$ & $\mathrm{n} / \mathrm{a}^{\mathrm{a}}$ & .19 \\
$\quad$ bottom & & & & \\
$\quad$ Send naked pictures or & $6(3)$ & $0.0(0)$ & $\mathrm{n} / \mathrm{a}^{\mathrm{a}}$ & .04 \\
$\quad$ sex movies of self & & & & \\
$\quad$ Send naked pictures or & $8(4)$ & $4.4(4)$ & $\mathrm{n} / \mathrm{a}^{\mathrm{a}}$ & .46 \\
$\quad$ sex movies of others & & & & \\
$\quad$ Cybersex & $12(6)$ & $2.2(2)$ & $\mathrm{n} / \mathrm{a}^{\mathrm{a}}$ & .02 \\
$\quad$ Any & $54(27)$ & $43.3(39)$ & 7.44 & .19 \\
\hline
\end{tabular}

${ }^{a}$ Not applicable, Fisher's exact was used

majority of boys in both groups disapproved of sexual contacts with many different partners in both boys and girls (ASD $68 \%$ in the case of girls and $62 \%$ for boys). The boys with ASD were significantly less disapproving towards homosexuality (acceptance of homosexuality). More boys with ASD (76\%) approved sexual contact between two boys, compared with controls $(37.8 \%)\left(\chi^{2}(1)=18.8\right.$, $p<.01$, Cramer's $V=.37$ ). The majority of boys in both the ASD and control group felt positive about sexual contacts between two girls (ASD $92 \%$, control $78.9 \%$ ). The boys with ASD and controls disagreed with negative statements relating to sexuality and had a neutral or positive response to positive sexuality-related statements.

\section{Internet and Sexually Explicit Materials}

About half of the boys with ASD talked about sex on the internet in the previous 6 months (Table 4).
The boys with ASD viewed explicit sexual images in porn magazines (36\%), in video clips containing nudity $(70 \%)$, in sex movies $(22 \%)$, and on porn websites (76\%). Most boys viewed any of the sexually explicit media ( $86 \%$ ) and about half (54\%) of the boys with ASD used the internet for at least one sexuality-related activity. Participants with ASD and controls did not significantly differ $(p>.01)$ regarding their experience with sexual explicit media and sexuality on the internet.

\section{Discussion}

The aim of this study was to enhance insight into sexual and relational experiences in a group of high-functioning adolescent boys with ASD. The results of this study confirm the expectations of a high prevalence of solo sexual behaviours (H1) but refute earlier assumptions regarding fewer partnered sexual experiences (Hellemans et al. 2007), later sexual debut (Stokes and Kaur 2005) (H2) and higher frequency of same-sex feelings or experiences (H4) in boys with ASD when compared with boys in the general population. Sexual victimization and offending (H3) were hardly found. Both groups had permissive attitudes towards sexuality, no explicit gender role expectations, and higher positive and lower negative attitudes towards sexuality. The participants with ASD were significantly more accepting towards homosexuality, compared to controls. Finally, the internet has become an arena for sexualityrelated exchanges for all adolescents, including those with ASD.

The results of this study support the earlier findings by Hellemans et al. (2007) on age-appropriate sexual experience in high-functioning boys with ASD and reveal no differences in lifetime sexual experience of boys with ASD and their peers in the general population. The higher frequencies regarding sexual experience in this study compared with findings of earlier studies (Haracopos and Pedersen 1992; Hellemans et al. 2007) are due, at least partly, to the use of self- versus parent- or caregiver-report. These observers frequently stated that they had insufficient knowledge of specific behaviours or feelings of the children under study (Hellemans et al. 2007). Clearly, 
self-report by boys with ASD may be considered more accurate than reports by parents or caregivers.

\section{Adolescent Sexuality and ASD}

Based on the results of this study, a typical high-functioning adolescent boy with ASD starts masturbating at around age 13, falls in love in the same period and experiences his first orgasm shortly afterwards. Before the age of 16 , he has a relationship with a girl and starts kissing and petting. One in 10 boys doubts his preference for girls or has fantasies about sex with another boy The typical boy with ASD thinks positively about sex, is rather permissive and is not bothered about same-sex interests of peers. A substantial part (20-34\%) has experienced other partnered sexual behaviours (manual and oral sex) and one in five has sexual intercourse in this period. The boys will probably have viewed sexually explicit materials and half of them used the internet for sexual means. The prevalence of sexrelated problems in adolescents needs further attention in research.

Although the results of this study demonstrated comparable trajectories in the sexual development of boys with ASD and their peers in the general population, differences cannot be ruled out. The results of this study do not offer information on the frequency, context or quality of the different sexual experiences since only the presence or absence of experiences was questioned. Remarks and questions by the boys with ASD during data collection indicated that some of them had indeed experienced concerns or behaved in inappropriate ways. Taken together, ASD features seem not to influence whether high functioning adolescent boys with ASD have solo and partnered sexual experience; however, little is known about how, in which circumstances and with whom.

The results of this study highlight the importance of sex education for high-functioning adolescent boys with ASD in order to support their sexual development as a positive part of human functioning. This study also has implications for the age at which to offer sex education. In contrast with earlier findings (Stokes and Kaur 2005), no delay in sexual debut was found. Sex education attuned to the developmental stage of boys with ASD should support these boys to understand their bodily changes and sexual reactions, feelings and behaviours. Given the social, communicative and behavioural features inherent in ASD, sex education should be tailored to the specific impairments and needs of these boys in order to strengthen their insight and skills when starting romantic relationships and enable them to enjoy sexuality in a safe and respectful way. Attention should be given to solo as well as partnered sexuality, in real life and online. It is possible, in contradiction with earlier findings (Mazurek et al. 2012), that online contacts are easier to make or more appealing than face-to-face contacts for some boys in the ASD group and can be a "window on the world", offering a way to initiate romantic and sexual contacts. Different risks relating to online sexuality-related activities for boys with ASD could be imagined, however only a small number of boys with ASD reported online behaviours that may cause concern.

\section{Same-Sex Feelings and ASD}

This study did not confirm earlier findings regarding a higher prevalence of homosexual feelings and behaviours in boys with ASD (Gilmour et al. 2012; Hellemans et al. 2007). However, the ASD group was far more tolerant than the control group towards homosexuality in society. It is not clear how this difference in tolerance can be explained. Different mechanisms may be at work: lower sensitivity to social norms and stereotyped gender roles in the boys with ASD, a higher tolerance for being different, a socially desirable response style, lower recognition of their own sexual preferences, or having more homosexual feelings themselves. Conversely, a greater tolerance of homosexuality could make same-sex experimentation more acceptable, but this is not reflected in same-sex experiences in this study. Attention to this topic in education is, however, advisable.

\section{Victimisation, Offending and ASD}

Earlier findings relating to a high prevalence of sexual victimisation in people with ASD (Mandell et al. 2005) were not confirmed in this sample. Recruitment strategies might be of influence: Mandell et al. (2005) studied children in mental health services who might have suffered more victimisation, while not all of this study's participants received mental health care. Furthermore, it is possible that victims might have refused to participate in our study. Sexual offending was also hardly found in this study. Only a very small number of boys in the ASD group reported having forced another into sexual activities, which puts earlier findings on the relation between ASD features in boys accused of sex offences ('t Hart-Kerkhoffs et al. 2009) into perspective. Earlier studies showed a comparable and even higher percentage of boys in the general population who confirmed that they had forced someone into sexual behaviours, ranging from $3.6 \%$ of boys in the Netherlands (de Graaf et al. 2012) to $12 \%$ in a Norwegian group of boys (Seto et al. 2010).

Limitations, Strengths, and Further Research

The results should be interpreted in light of the strengths and limitations of this study. Characteristics of the ASD 
group might limit generalizability. The low ADOS scores might indicate that some of the participants had only mild ASD features. A substantial proportion of the boys with ASD had comorbid disorders, especially ADHD, which possibly influenced their sexual functioning. For example, Flory et al. (2006) found an increased likelihood for adolescents with (comorbid) ADHD to engage in risky sexual behaviours. Given that a quarter of the boys with ASD, in this study, had comorbid ADHD, this finding might have resulted in an overestimation of sexual experience compared to boys with ASD without ADHD. Recruitment bias could also have influenced the results of this study; people volunteering in sex research are more open to sexuality, have more sexual experience (Bogaert 1996), less guilt (Strassberg and Lowe 1995), less conservative sexual opinions, more novelty-seeking behaviour, earlier onset of sexual behaviour, and more adverse sexual experiences (Dunne et al. 1997). However, Dunne et al. (1997) stated that the differences between participants' and non-participants' reports were small and the more experienced participants tend to underreport. Different parents refused to let their sons participate in this study, stating that the boys were not interested in sexuality. This might have resulted in the selection of boys with ASD who were more interested in sexuality than others, resulting in an overestimation of lifetime sexual experience. On the other hand, in the general population, parents tend to underestimate the sexual experience of their children (Jaccard et al. 1998; Mollborn and Everett 2010). Other reasons for non-participation, such as negative feelings relating to sexuality or the psychological condition of the boys, might also have biased this study's results. For example, boys that were abused or had offended, and boys that experienced uncertainty relating to sexuality could have declined participation.

Notwithstanding the efforts made to minimize report bias (Tourangeau and Yan 2007), its influence on a sensitive issue such as sexuality cannot be ruled out. In addition, this survey did not contain questions on some specific sexual behaviours (e.g., paraphilias and compulsive masturbation), although they were found in earlier studies of people with ASD. Finally, the absence of significant differences in sexual experience between the boys with ASD and the controls could be due to the selection and the experience of the control group. The proportion of boys in the control group who had sexual intercourse is lower than the findings of de Graaf et al. (2012) (38\% of boys aged 15-18), but comparable with findings of the National Survey of Sexual Health and Behavior (http://www.natio nalsexstudy.indiana.edu). If the boys in the control group were less sexually experienced than their peers, it might be possible that partnered sexual behaviours are less common in boys with ASD than in boys in the general population.
Notwithstanding these limitations, this study is, to the best of our knowledge, the first to describe self-reported relational and sexual functioning, and opinions about sexuality in high-functioning adolescent boys with ASD. This offers a unique insight into their experience, beliefs and behaviour relating to sexuality.

Replication of these findings in other ASD samples of all cognitive and functional levels is needed. In addition, several questions for further research remain. Follow-up and qualitative studies are necessary to gain more in-depth insight into boys' sexual development and well-being. The role of the context (e.g., growing up in a relatively conservative family where sexuality may be less easily discussed) or the availability of sex education is another domain for further study. In addition, longitudinal studies are needed to explore sexual development. Developmental differences between boys who have more versus less sexual experience or who avoid sexuality might offer clues for intervention and support. Finally, sexual development in female adolescents with ASD remains understudied.

\section{Conclusion}

This study demonstrated that having ASD has little influence on the lifetime experience of sexual behaviours, feelings and attitudes in high-functioning adolescent boys. The findings of this study refute the old asexuality beliefs as well as put the deficit discourse on ASD and sexuality into perspective (Bertilsdotter Rosqvist 2013; Koller 2000; Torisky and Torisky 1985). In addition, our results counter the earlier findings that adolescents with ASD are delayed in their sexual development (Stokes and Kaur 2005). The results of this study broaden recent findings on positive sexual functioning in adults to adolescents with ASD (Byers et al. 2013). However, some boys might experience or demonstrate sexual problems, as was indicated by the remarks and questions of some of the boys with ASD in this study and based on the existing case reports. Taken together, we are convinced that an integrated approach (Tolman and McClelland 2011) seems justified-i.e., accepting sexuality as a normative part of adolescent development while also giving attention to the possible impact of ASD features on learning and daily functioning relating to sexuality. Education and communication regarding sexuality is thus as important for boys with ASD as it is for their peers. Early attention to sexuality can prepare adolescents with ASD to understand their sexual development and enhance a positive sexual development. Open and concrete communication about sexuality with adolescent boys with ASD offers them the opportunity to raise questions and to discuss worries or difficulties. Parents, caregivers and mental health professionals should be prepared and trained to support children and adolescents with 
ASD in their sexual development as a normative and positive part of these adolescents' functioning.

Acknowledgments We are most grateful to all boys and their parents who participated in this study. The authors also would like to thank Hanneke De Graaf, Rutgers WPF, for sharing the SO25II questionnaire and data. Also thanks to Karin Brouwers and colleagues at Koninklijke Kentalis, Eindhoven; Liesbeth Van Vught and colleagues at Pleinschool Helder, Eindhoven; Jan Wijnja and colleagues at VSO De Korenaer, Eindhoven; Karien de Jonge and colleagues at Herlaarhof, Vught; Sussiel Brands at Leo Kannerhuis Brabant, Tilburg; Sanne Herpers and MJ Verhappen at GGzOostbrabant and our colleagues at UKJA, Antwerpen and GGzE. No grants or support were received for this work. This research project was part of the requirements to fulfil the postacademic specialist training in Clinical Psychology at Rino Zuid, Eindhoven, The Netherlands.

\section{References}

American Psychiatric Association. (2000). Diagnostic and statistical manual of mental disorders (4th ed., text rev.). Washington, DC: American Psychiatric Association.

Baron-Cohen, S. (1988). An assessment of violence in a young man with Asperger's syndrome. Journal of Child Psychology and Psychiatry, 29, 351-360.

Bastiaansen, J. A., Meffert, H., Hein, S., Huizinga, P., Ketelaars, C., Pijnenborg, M., et al. (2011). Diagnosing autism spectrum disorders in adults: The use of Autism Diagnostic Observation Schedule (ADOS) module 4. Journal of Autism and Developmental Disorders, 41(9), 1256-1266.

Bertilsdotter Rosqvist, H. (2013). Becoming an "autistic couple": Narratives of sexuality and couplehood within the Swedish autistic self-advocacy movement. Sexuality \& Disability. Advance online publication. doi:10.1007/s11195-013-9336-2.

Bleil Walters, J., Hughes, T. L., Sutton, L. R., Marshall, S. N., Crothers, L. M., Lehman, C., et al. (2013). Maltreatment and depression in adolescent sexual offenders with an autism spectrum disorder. Journal of Child Sexual Abuse, 22(1), 72-89.

Bogaert, A. F. (1996). Volunteer bias in human sexuality research: Evidence for both sexuality and personality differences in males. Archives of Sexual Behavior, 25(2), 125-140.

Braun-Courville, D. K., \& Rojas, M. (2009). Exposure to sexually explicit web sites and adolescent sexual attitudes and behaviors. Journal of Adolescent Health, 45(2), 156-162.

Byers, E. S., Nichols, S., \& Voyer, S. D. (2013). Challenging stereotypes: Sexual functioning of single adults with high functioning autism spectrum disorder. Journal of Autism and Developmental Disorders, 43, 2617-2627.

Byers, E. S., Nichols, S., Voyer, S. D., \& Reilly, G. (2012). Sexual well-being of a community sample of high-functioning adults on the autism spectrum who have been in a romantic relationship. Autism, 17(4), 418-433.

Chan, L. G., \& Saluja, B. (2011). Sexual offending and improvement in autistic characteristics after acquired brain injury: A case report. The Australian and New Zealand Journal of Psychiatry, 45, 902-903.

Cohen, J. (1988). Statistical power analysis for the behavioral sciences (2nd ed.). Hillsdale, NJ: Lawrence Erlbaum Associates.

Cooper, S., Mohamed, W. N., \& Collacott, R. A. (1993). Possible Asperger's syndrome in a mentally handicapped transvestite offender. Journal of Intellectual Disability Research, 37, 189-194.

de Graaf, H., Kruijer, H., Van Acker, J., \& Meijer, S. (2012). Seks onder je 25e: Seksuele gezondheid van jongeren in Nederland anno 2012 [Sex under the age of 25: Sexual health among youth in the Netherlands in 2012]. Delft, The Netherlands: Eburon.

de Vries, A. L., Noens, I. L., Cohen-Kettenis, P. T., Van BerckelaerOnnes, I. A., \& Doreleijers, T. A. (2010). Autism spectrum disorders in gender dysphoric children and adolescents. Journal of Autism and Developmental Disorders, 40(8), 930-936.

Dewinter, J., Vermeiren, R., Vanwesenbeeck, I., \& van Nieuwenhuizen, C. (2013). Autism and normative sexual development: A narrative review. Journal of Clinical Nursing, 22, 3467-3483.

Diamond, L. M., \& Savin-Williams, R. C. (2009). Adolescent sexuality. In R. M. Lerner \& L. Steinberg (Eds.), Handbook of adolescent psychology, volume 1: Individual bases of adolescent development (3rd ed.), (pp. 479-523). Hoboken, NJ: Wiley.

Dunne, M. P., Martin, N. G., Bailey, J. M., Heath, A. C., Bucholz, K. K., Madden, P. A., et al. (1997). Participation bias in a sexuality survey: Psychological and behavioural characteristics of responders and non-responders. International Journal of Epidemiology, 26(4), 844-854.

Flory, K., Molina, B. S. G., Pelham, W. E., Gnagy, E., \& Smith, B. (2006). Childhood ADHD predicts risky sexual behavior in young adulthood. Journal of Clinical Child and Adolescent Psychology, 35(4), 571-577.

Fortenberry, J. D. (2013). Puberty and adolescent sexuality. Hormones and Behavior, 64(2), 280-287.

Gabriels, R. L., \& Van Bourgondien, M. E. (2007). Sexuality and autism: Individual, family, and community perspectives and interventions. In R. L. Gabriels \& D. E. Hill (Eds.), Growing up with autism: Working with school-age children and adolescents (pp. 58-72). London, UK: The Guilford Press.

Gilmour, L., Schalomon, P. M., \& Smith, V. (2012). Sexuality in a community based sample of adults with autism spectrum disorders. Research in Autism Spectrum Disorders, 6(1), 313-318.

Gotham, K., Risi, S., Pickles, A., \& Lord, C. (2007). The Autism Diagnostic Observation Schedule: Revised algorithms for improved diagnostic validity. Journal of Autism and Developmental Disorders, 37(4), 613-627.

Griffin-Shelley, E. (2010). An Asperger's adolescent sex addict, sex offender: A case study. Sexual Addiction \& Compulsivity, 17, 46-64.

Haracopos, D., \& Pedersen, L. (1992). Sexuality and autism: The Danish report. Unpublished manuscript. http://www.autismuk. com/?page_id=1293. Accessed October 22, 2012.

Hellemans, H., Colson, K., Verbraeken, C., Vermeiren, R., \& Deboutte, D. (2007). Sexual behavior in high-functioning male adolescents and young adults with autism spectrum disorder. Journal of Autism and Developmental Disorders, 37(2), 260-269.

Hénault, I., \& Attwood, T. (2006). The sexual profile of adults with Asperger's syndrome: The need for support and intervention. In I. Hénault (Ed.), Asperger's syndrome and sexuality: From adolescence through adulthood (pp. 183-192). London, UK: Jessica Kingsley Publishers.

Jaccard, J., Dittus, P. J., \& Gordon, V. V. (1998). Parent-adolescent congruency in reports of adolescent sexual behavior and in communications about sexual behavior. Child Development, 69(1), 247-261.

Kohn, Y., Tarek, F., Ratzoni, G., \& Apter, A. (1998). Aggression and sexual offense in Asperger's syndrome. The Israel Journal of Psychiatry and Related Sciences, 35, 293-299.

Koller, R. (2000). Sexuality and adolescents with autism. Sexuality and Disability, 18, 125-135.

Levy, S., Mandell, D., \& Schultz, R. (2009). Autism. The Lancet, 374(9701), 1627-1638.

Lord, C., Rutter, M., Dilavore, P. C., \& Risi, S. (1999). Autism Diagnostic Observation Schedule: Manual. Los Angeles, CA: Western Psychological Services. 
Mandell, D. S., Walrath, C. M., Manteuffel, B., Sgro, G., \& PintoMartin, J. A. (2005). The prevalence and correlates of abuse among children with autism served in comprehensive community-based mental health settings. Child Abuse and Neglect, 29(12), 1359-1372.

Mazurek, M. O., Shattuck, P. T., Wagner, M., \& Cooper, B. P. (2012). Prevalence and correlates of screen-based media use among youths with autism spectrum disorders. Journal of Autism and Developmental Disorders, 42(8), 1757-1767.

Mehtar, M., \& Mukaddes, N. M. (2011). Posttraumatic stress disorder in individuals with diagnosis of autistic spectrum disorders. Research in Autism Spectrum Disorders, 5(1), 539-546.

Milton, J., Duggan, C., Latham, A., Egan, V., \& Tantam, D. (2002). Case history of co-morbid Asperger's syndrome and paraphilic behaviour. Medicine, Science and Law, 42, 237-244.

Mollborn, S., \& Everett, B. (2010). Correlates and consequences of parent-teen incongruence in reports of teens' sexual experience. Journal of Sex Research, 47(4), 314-329.

Moore, S., \& Rosenthal, D. (2006). Sexuality in adolescence: Current trends. Hove, UK: Taylor \& Francis.

Murrie, D. C., Warren, J. I., Kristiansson, M., \& Dietz, P. E. (2002). Asperger's syndrome in forensic settings. International Journal of Forensic Mental Health, 1, 59-70.

Ousley, O. Y., \& Mesibov, G. B. (1991). Sexual attitudes and knowledge of high-functioning adolescents and adults with autism. Journal of Autism and Developmental Disorders, 21(4), 471-481.

Ray, F., Marks, C., \& Bray-Garretson, H. (2004). Challenges to treating adolescents with Asperger's syndrome who are sexually abusive. Sexual Addiction \& Compulsivity, 11, 265-285.

Rutter, M., Le Couteur, A., \& Lord, C. (2003). Autism Diagnostic Interview-Revised (ADI-R) manual. Los Angeles, CA: Western Psychological Services.

Seto, M. C., Kjellgren, C., Priebe, G., Mossige, S., Svedin, C. G., \& Långström, N. (2010). Sexual coercion experience and sexually coercive behavior: A population study of Swedish and Norwegian male youth. Child Maltreatment, 15, 219-228.

Silva, J. A., Ferrari, M. M., \& Leong, G. B. (2002). The case of Jeffrey Dahmer: Sexual serial homicide from a neuropsychiatric developmental perspective. Journal of Forensic Sciences, 47, 1347-1359.

Smith, L. H., Guthrie, B. J., \& Oakley, D. J. (2005). Studying adolescent male sexuality: Where are we? Journal of Youth and Adolescence, 34(4), 361-377.

Stokes, M., \& Kaur, A. (2005). High-functioning autism and sexuality: A parental perspective. Autism, 9(3), 266-289.

Stokes, M., Newton, N., \& Kaur, A. (2007). Stalking, and social and romantic functioning among adolescents and adults with autism spectrum disorder. Journal of Autism and Developmental Disorders, 37(10), 1969-1986.

Strassberg, D. S., \& Lowe, K. (1995). Volunteer bias in sexuality research. Archives of Sexual Behavior, 24(4), 369-382.

't Hart-Kerkhoffs, L. A., Jansen, L. M., Doreleijers, T. A., Vermeiren, R., Minderaa, R. B., \& Hartman, C. A. (2009). Autism spectrum disorder symptoms in juvenile suspects of sex offenses. The Journal of Clinical Psychiatry, 70(2), 266-272.

Tolman, D. L., \& McClelland, S. I. (2011). Normative sexuality development in adolescence: A decade in review, 2000-2009. Journal of Research on Adolescence, 21(1), 242-255.

Tolman, D. L., Striepe, M. I., \& Harmon, T. (2010). Gender matters: Constructing a model of adolescent sexual health. Journal of Sex Research, 40, 37-41.

Torisky, D., \& Torisky, C. (1985). Sex education and sexual awareness building for autistic children and youth: Some viewpoints and considerations. Journal of Autism and Developmental Disorders, 15(2), 213-227.

Tourangeau, R., \& Yan, T. (2007). Sensitive questions in surveys. Psychological Bulletin, 133(5), 859-883. 